\title{
Finite Element Investigation of Moment Effect on Fretting Fatigue
}

\author{
Behnam Hajshirmohammadi ${ }^{1}$, Mohammad Mehdizadeh ${ }^{2}$ \\ ${ }^{1,2}$ Mechanical Engineering department, Louisiana State university, Baton Rouge, USA
}

\begin{abstract}
Fretting fatigue is a degrading process which is responsible for considerable amount of mechanical structure failure every year. In the present study, a finite element model is proposed to show the effect of a bending moment on a flat surface under fretting loading. The results show that the bending moment has a major effect on the friction stress distribution on the surface of the two solids under contact. Finite element analysis predicts an increased damage effect on the surface of solids when a load is applied as a pure moment. The results predict elevation in the relative slip between the surfaces after applying the bending moment.
\end{abstract}

KEYWORDS: Finite element, Fretting

\begin{tabular}{|c|c|c|c|}
\hline \multicolumn{4}{|l|}{ Nomenclature } \\
\hline$a$ & $\begin{array}{l}\text { Contact area half } \\
\text { length }(\mathrm{m})\end{array}$ & $P r$ & Pressure on sides of flat $(\mathrm{Pa})$ \\
\hline$r$ & Radius of cylinder (m) & $t$ & Flat thickness (m) \\
\hline$F$ & Normal force $(\mathrm{N})$ & $b$ & Flat width (m) \\
\hline$P$ & Pressure $(\mathrm{Pa})$ & & \\
\hline$P_{0}$ & $\begin{array}{l}\text { Maximum pressure in } \\
\text { hertz formula }(\mathrm{Pa})\end{array}$ & $\delta$ & Relative slip of surfaces. (m) \\
\hline$E$ & Elastic modulus (GPa) & $\tau$ & Contact shear stress (MPa) \\
\hline$v$ & Poison's ratio & & \\
\hline$M$ & Moment (N.m) & & \\
\hline
\end{tabular}

\section{INTRODUCTION}

Fatigue is a process which involves degradation of material and energy dissipation [1]. Fatigue process has three main stages. In the first stage, stress and strain field inside material results in initiation of crack which is followed by second stage of forming macro crack. These macro cracks finally propagates and fracture happens [1-6].

Fretting is generally described as a small oscillation of two solids which are in contact. When two solids have contact on the surface, the reaction between them is a distribution of stress in form of traction and normal pressure. The distribution of mechanical stress in contact region depends on the geometry of the bodies and the mechanical properties of the utilized material [7, 8] . Due to the multi-scale and multi-physics nature of the contact mechanism, it is still a growing field of research. Hertz [9] proposed the first relation for the pressure distribution of contact zone. The potential of Hertz formula was further shown in the contact problems in railways, gears and bearing industries. With the advent of powerful computation tools, contact problem became again the topic of studies. Finite element also has been an efficient approach for analysis of contact problems. Finite element approach has been widely used in fretting and wear [10,11]. Finite element approach has shown it efficiency in composite also [12$15]$.

Fretting has the nature of dissipation and degradation which means that during fretting entropy is generated. The generation of entropy during fatigue can be attributed to the crack propagation also[16]. However, in the finite element analysis, the stress-strain approach is the only method which can predict the location of crack initiation on the contact region.

In a number of studies, fretting fatigue has been investigated as a cylinder on flat where the normal stress is applied on the flat. This is supposed to be a prevalent case when two sliding bodies have contact. However, the presence of a pure moment on the flat can critically change the stress distribution which can alter the location of crack nucleation sight and subsequently the fatigue life of the 


\section{International Journal of Current Science Research and Review}

ISSN: 2581-8341

Volume 04 Issue 04 April 2021

DOI: 10.47191/ijcsrr/V4-i4-04, Impact Factor: 5.825

IJCSRR@ 2021

www.ijcsrr.org

specimen. The present study uses an ABAQUS code to analyze the contact stress between a half cylinder and a flat surface. The two bodies are assumed to react elastically as the results of stress and have the same material properties.[1, 17]

Fig. 1 shows the schematic of a sample under fretting fatigue. As it is shown the pads are pushed on the surface of specimen and the flat is under tension-compression load. The specific locations under the pads are the candidates for crack initiation and the final failure happens due to the propagated crack.

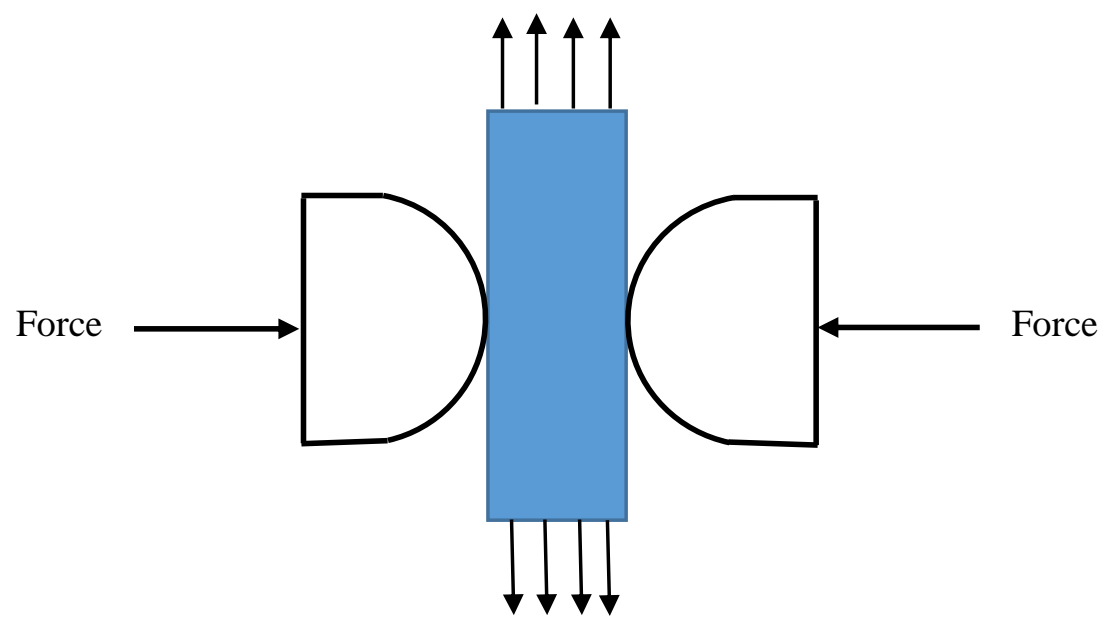

Figure 1. The schematic of fretting fatigue on a flat specimen.

\section{THEORY AND FORMULATION}

The schematic of the contact problem is shown in Fig. 2. As it is illustrated, normal force is applied on the top surface of the half cylinder and the oscillation takes place in the same plane in horizontal direction. The length of contact region is shown by $2 a$ and cylinder has radius of $r$. The normal force is given as $F$. Using the Hertz formula, one can predict pressure distribution and maximum pressure between the surfaces as the following.

$$
\begin{aligned}
& P(x)=P_{0}\left\{1-\left(\frac{x}{a}\right)^{2}\right\}^{1 / 2} \\
& P_{0}=\left(\frac{P E}{2 \pi\left(1-v^{2}\right) r}\right)^{1 / 2}
\end{aligned}
$$

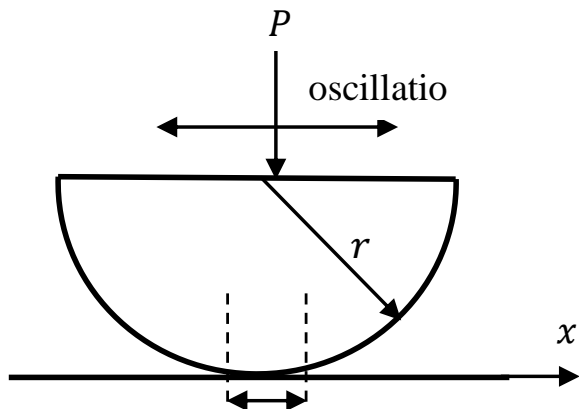

$2 a$

Figure 2. Schematic of fretting contact 


\section{International Journal of Current Science Research and Review}

ISSN: 2581-8341

Volume 04 Issue 04 April 2021

DOI: 10.47191/ijcsrr/V4-i4-04, Impact Factor: 5.825

IJCSRR@ 2021

www.ijesrr.org

$P$ denotes the pressure distribution and $P_{0}$ is the maximum of pressure distribution which happens in the center of contact area. $E$ is the elastic modulus and Poison's ratio is given as $v$.

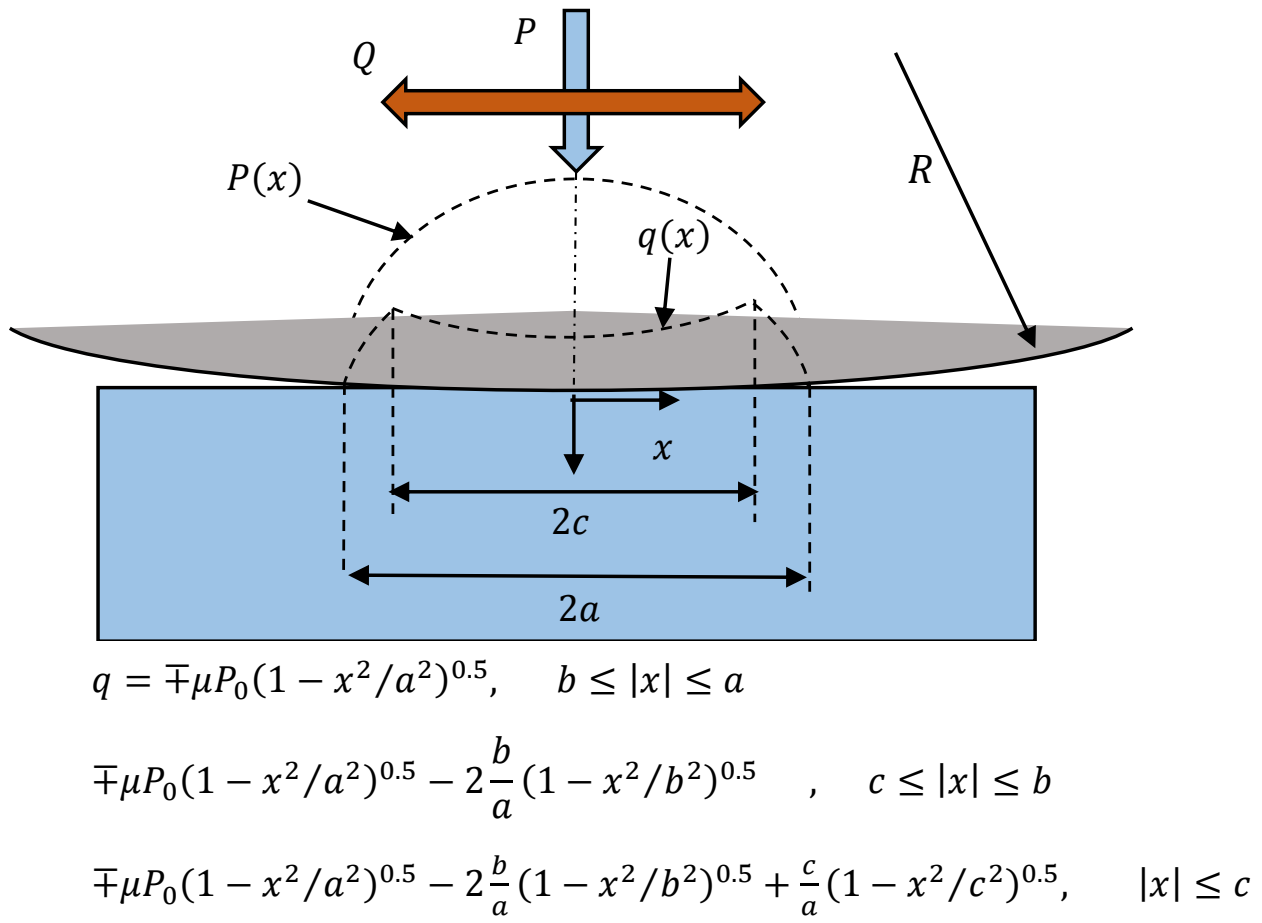

Figure 3. Schematic of fretting contact.

Depending on the amount of horizontal load, there will be two different type of fretting. In low horizontal loads, the two surfaces stick together in the central region $(c \leq|x| \leq b)$ of contact as shown in Fig. 3. At the two ends of contact region $(|x| \leq c)$, the surfaces slightly slide on each other. This type of fretting is called partial slip. Once the horizontal load increases, the central stick region becomes smaller and if the friction force is not enough to make the surfaces stick together, the two surfaces slide on each other. This is called gross slip. The friction force distribution is found according to the relations given in Fig. 3 . This is seen that the profile of friction force on the flat has a discontinuity at the boundary of stick/partial slip zone at $\mathrm{x}=\mp \mathrm{c}$. This point is the most probable location for accumulation of vacancies and initiation of crack. This means that the value of stress at these point determine fatigue life of components under fretting loading.

\subsection{Numerical approach}

The procedure of solving contact problem is carried out by a FEA model in ABAQUS commercial software. The contact problem is solved by considering two bodies of master and slave surfaces. In the present analysis, the flat is considered the master surface and the cylinder is the slave (Fig. 4). To make sure that results are reliable, a process of mesh refining is done and the convergence of the results are evaluated. The friction coefficient is assumed to be 0.5 and fine mesh is used for the contact region. To decrease the computation time, the area which is not in contact is meshed with course elements. 


\section{International Journal of Current Science Research and Review}

ISSN: 2581-8341

Volume 04 Issue 04 April 2021

DOI: 10.47191/ijcsrr/V4-i4-04, Impact Factor: 5.825

IJCSRR@ 2021

www.ijcsrr.org

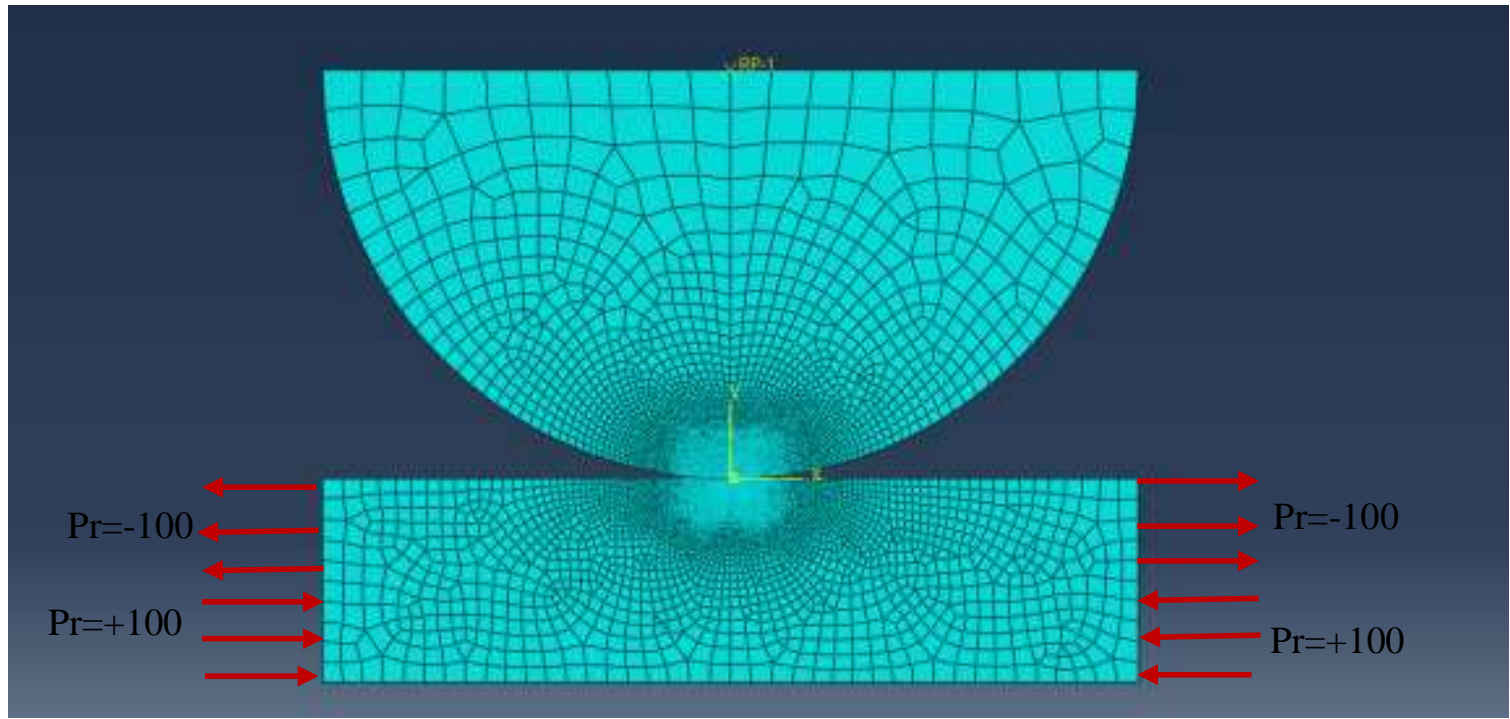

Figure 4. Application of moment using surface pressure on the flat.

\section{RESULTS AND DISCUSSION}

To validate the present finite element analysis, the results of the simulation is compared with [18] for fretting without moment. Precise and complete finite element modeling of an engineering problem has proved to influence the accuracy of its solution [11, 19-24]. The finite element model is executed in three steps. In the first step, the normal load is applied on the center of cylinder. The boundary condition considered in the first step is no displacement on the horizontal and vertical direction of nodes on the sides and bottom of the flat. To avoid movement rotation of the cylinder during first step, a constraint is applied on the center point where load is acting on cylinder. A Multi-Point Constraint scheme is used to restrict rotational movement of all the nodes on top of the cylinder to the rotation of center point. In the second step, the shear force is applied on the central point on top of the cylinder. Norotation constraint is kept active for the load point in the second step. The boundary condition of no displacement is implemented on the right and left sides of the flat surface. In the third step, the boundary condition of no displacement is deactivated for the side surfaces of the flat. In order to apply the moment on the flat, two couple pressure is loaded on the sides of the flat. Because the value of the linear pressure is equal on the both sides, the net force is zero and the only effect of pressure on the side surfaces is the moment. The value of this moment is found by the following relation.

$$
M=\operatorname{Pr}(t / 2)^{2}
$$

where $\operatorname{Pr}$ is the pressure on the sides and $t$ is the is the thickness of the flat. The element shape for mesh type is Quad-dominated mesh. Structured mesh is used for the area around the contact region and the free mesh type is used for the area away from the contact region. Explicit linear element is applied on both cylinder and flat. The plain-strain condition is considered for the both bodies.

Mechanical properties of the flat and cylinder is given in the following table 1.

Table.1

\begin{tabular}{|c|c|c|c|c|c|c|}
\hline$E$ & $F$ & Q & $R$ & $v$ & $t$ & $b$ \\
\hline $72.1 \mathrm{GPa}$ & $150 \mathrm{~N}$ & $50 \mathrm{~N}$ & $20 \mathrm{~mm}$ & 0.33 & $10 \mathrm{~mm}$ & $40 \mathrm{~mm}$ \\
\hline
\end{tabular}

The comparison of the results is shown in Fig. 5. The results are at the end of step 1 when the normal load is applied (Fig.5. b), when horizontal displacement is acting on the cylinder in the right direction (Fig. 5. c) and when the horizontal displacement is acting to the left direction (Fig. 5. a). 


\section{International Journal of Current Science Research and Review}

ISSN: 2581-8341

Volume 04 Issue 04 April 2021

DOI: 10.47191/ijcsrr/V4-i4-04, Impact Factor: 5.825

IJCSRR@ 2021

www.ijesrr.org
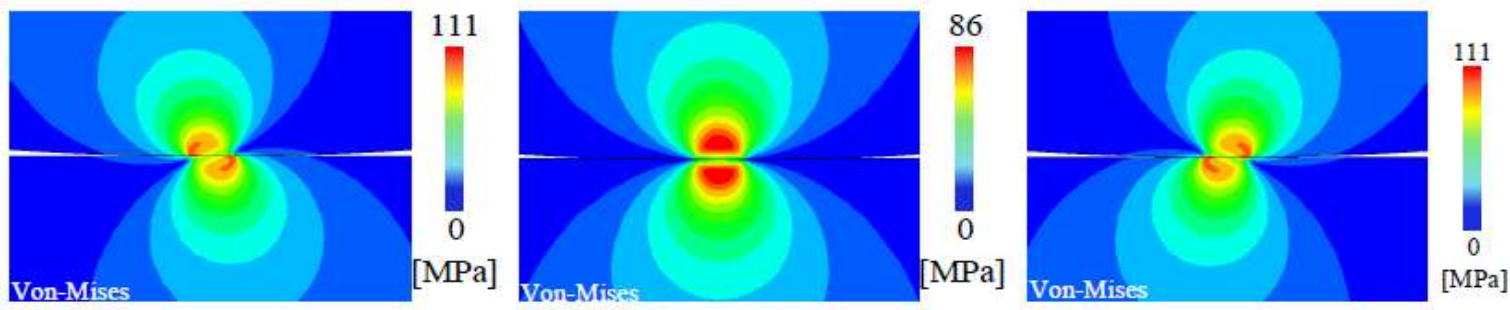

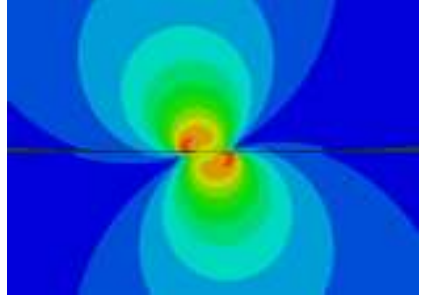

(a)

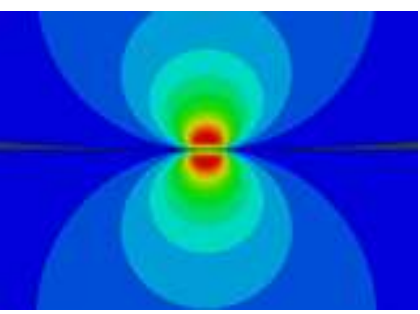

(b)

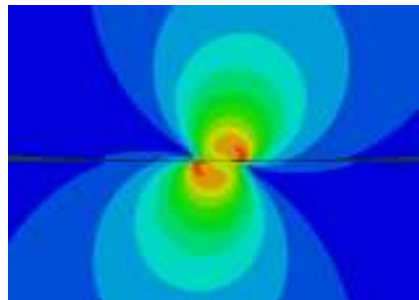

(c)

Figure. 5. Comparison of the present study and Talemi [18] for the case of fretting without moment on flat.

The comparison of the present model and the reference [18] are in good agreement.

The normal stress distribution in contact area is illustrated in the following figure. This is seen that application of moment on the flat has negligible effect on the pressure.

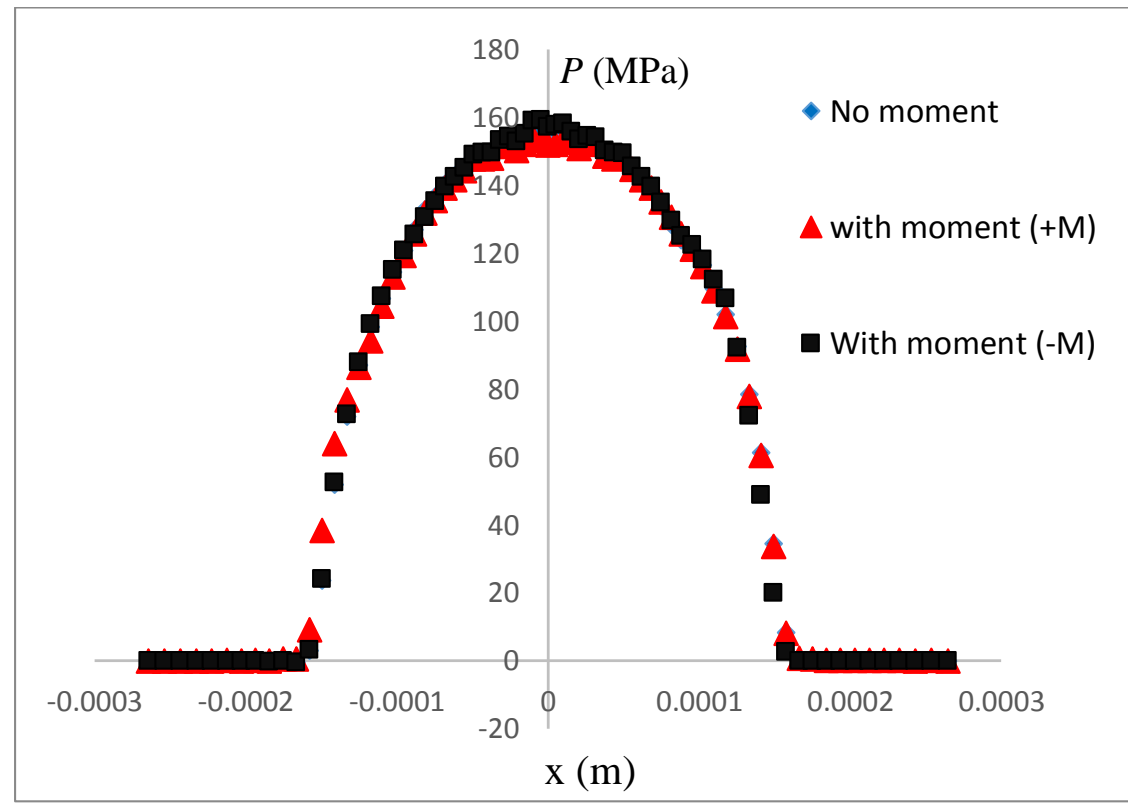

Figure. 6. Normal stress distribution comparison between the case without moment and case with the moment on the flat.

This result is due to the fact that normal stress distribution is mainly dependent on the value of the normal load appling on the contact surfaces. By bnforcing a moment on the flat and keeping the normal load constant, there would be not considerable change in the normal pressure distribution as it is seen in Fig. 6.

Fig. 7 shows the variation of shear stress in the contact region in three cases of $+\mathrm{M}$ moment, $-\mathrm{M}$ moment and no moment condition. This is seen that the moment changes the value of shear stress drastically. As it is shown in the figure, positive moment makes the stick region smaller and elevates the absolute value of shear stress on the right end of the stick zone. In the left side of stick zone, 


\section{International Journal of Current Science Research and Review}

ISSN: 2581-8341

Volume 04 Issue 04 April 2021

DOI: 10.47191/ijcsrr/V4-i4-04, Impact Factor: 5.825

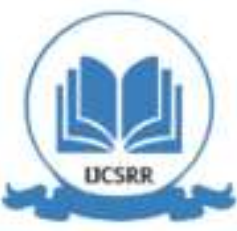

www.ijcsrr.org

the maximum value of the shear stress is lowered by the momen. This result shows that that the fatigue life is highly affected by the application of moment on the flat. This is due to the fact that the generally, crack initiation location is in the point where shear stress is maximum [25] in the contact region where is at the two ends of stick zone. When the flat surface experience no moment, both ends of the stick zone are suseptible for crack initiation with the same probability since the value of maximum shear stress is the same at the two sides of stick region. However, with the moment on the sides of flat, the maximum value of shear stress changes considerably. For the present loading condition, maximum shear stress increases around $\% 110$ for moment $+\mathrm{M}$ compared to no moment case. For the moment $-\mathrm{M}$, shear stress distribution is shown in the Fig. 7. This is seen that the maximum shear stress happpens in the left side of the stick zone. This is also found from the figure that shear stress which is applied by the shear load on the top of cylender is less than shear stress effect by the moment. This is the reason that the value of the shear stress is negative in a small region in the right side of contact zone for case $-\mathrm{M}$ and left side of contact zone for case with moment $+\mathrm{M}$.

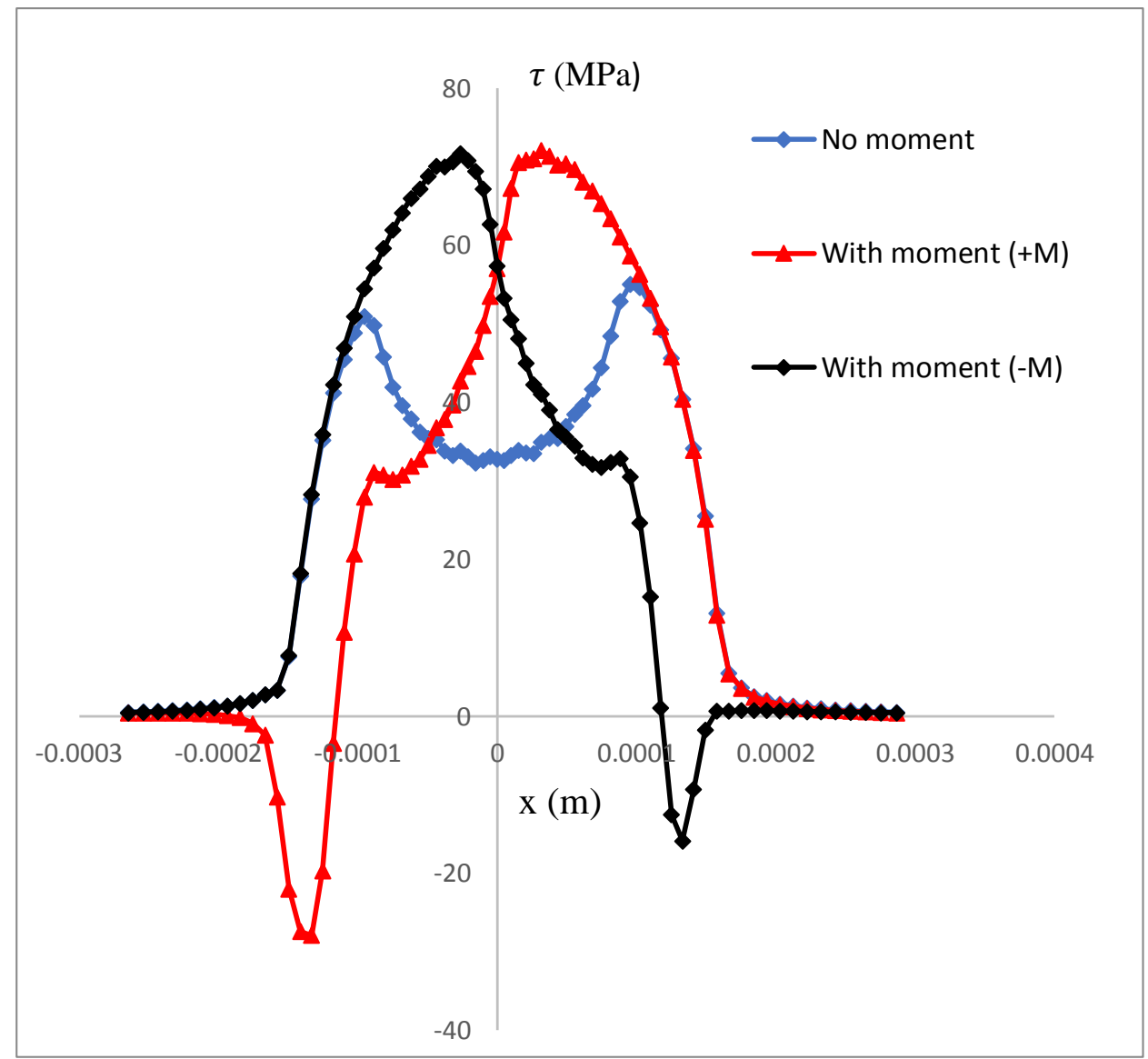

Figure.7. Shear stress distribution comparison between the case without moment and case with the moment on the flat.

As it was mentioned earlier, once shear load is applied on the cylender, if the value of shear load is small, stick zone is formed in the middle of contact region. The slip of the two surfaces in the stick region is zero. This stick zone is souraounder by an area where the two surfaces slide on each other and there will be a gross slip between the point in contact in that region. The relative slip value between the two surfaces in contacrt is illustrated in the folloing figure. This is obvious that for the case with no moment on the flat, the stick zone is symetric around the center line of contact zone. The slip value is considerably elevated between the surface when the moment applied on the flat surface. 


\section{International Journal of Current Science Research and Review}

ISSN: 2581-8341

Volume 04 Issue 04 April 2021

DOI: 10.47191/ijcsrr/V4-i4-04, Impact Factor: 5.825

IJCSRR@ 2021

www.ijesrr.org

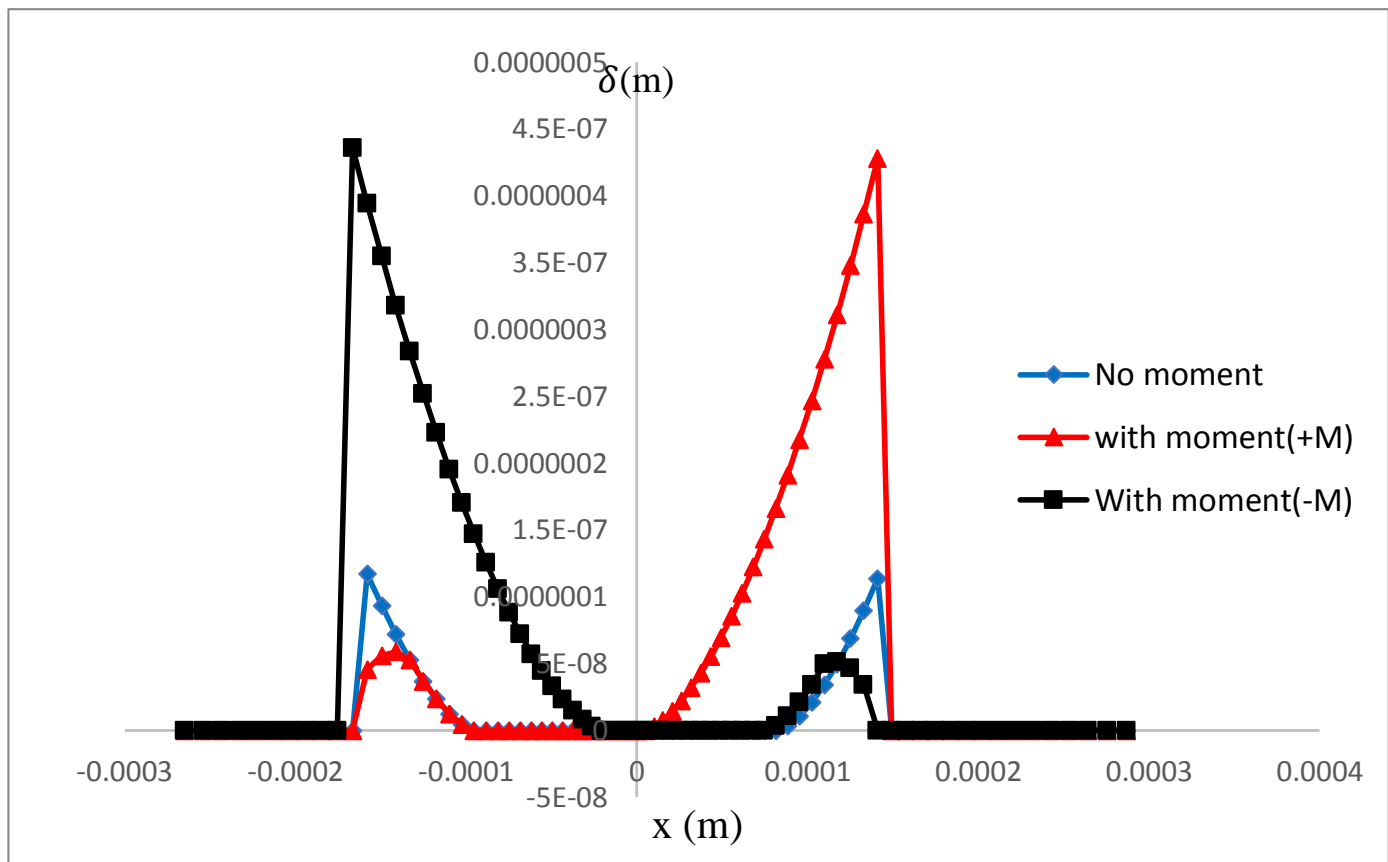

Figure. 8. Shear slip distribution comparison between the case without moment and case with the moment on the flat.

As it was expected, the relative displacement of the surfaces in the stick zone is zero which is illustrated in Fig. 8. The maximum amount of relative displacement is around 12 microns when no moment is applied while it can reach as high as 45 microns when the moment is applied.

\section{CONCLUSIONS}

A finite element model is presented to investigate effect of pure moment on the fretting fatigue stress distribution. The model predicts that shear stress in contact zone is elevated considerably at the boundary of stick/partial slip zone. The simulation also shows that pure moment can decrease the shear stress value in the partial slip zone. This reduction of shear stress results in negative value of shear stress in the present study. The results also propose negligible effect of moment on the normal stress distribution in the contact zone. Relative slip is influenced by the moment which leads to elevated value of slip between the surfaces at the boundary of stick/partial slip region.

\section{REFERENCES}

1. B. Hajshirmohammadi and M. Khonsari, "Thermographic evaluation of metal crack propagation during cyclic loading," Theoretical and Applied Fracture Mechanics, vol. 105, p. 102385, 2020.

2. B. Hajshirmohammadi and M. M. Khonsari, "Application of thermoelectricity in fatigue of metals," Fatigue \& Fracture of Engineering Materials \& Structures.

3. A. P. Jirandehi and T. Chakherlou, "A fatigue crack initiation and growth life estimation method in single-bolted connections," The Journal of Strain Analysis for Engineering Design, vol. 54, no. 2, pp. 79-94, 2019.

4. B. Mohammadi, M. Rohanifar, D. Salimi-Majd, and A. Farrokhabadi, "Micromechanical prediction of damage due to transverse ply cracking under fatigue loading in composite laminates," Journal of Reinforced Plastics and Composites, vol. 36, no. 5, pp. 377-395, 2017.

5. B. Koohbor, M. Rohanifar, and A. Kidane, "Characterizing fracture response of cracked transversely graded materials," Composite Structures, vol. 229, p. 111439, 2019.

6. J. Arashmehr, G. Rahimi, and S. Rasouli, "Numerical and experimental stress analysis of stiffened cylindrical composite shell under transverse end load," International Journal of Mechanical and Mechatronics Engineering, vol. 6, no. 7, pp. 1323-1327, 2012. 


\section{International Journal of Current Science Research and Review}

ISSN: 2581-8341

Volume 04 Issue 04 April 2021

DOI: 10.47191/ijcsrr/V4-i4-04, Impact Factor: 5.825

IJCSRR@ 2021

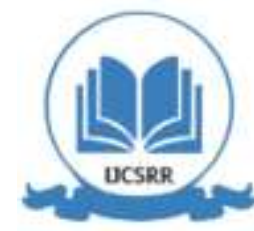

www.ijcsrr.org

7. D. Rahmatabadi, M. Tayyebi, N. Najafizadeh, R. Hashemi, and M. Rajabi, "The influence of post-annealing and ultrasonic vibration on the formability of multilayered Al5052/MgAZ31B composite," Materials Science and Technology, pp. 1-8, 2020.

8. N. Najafizadeh, M. Rajabi, R. Hashemi, and S. Amini, "Improved microstructure and mechanical properties of sheet metals in ultrasonic vibration enhanced biaxial stretch forming," Journal of Theoretical and Applied Vibration and Acoustics, vol. 5, no. 1, pp. 1-10, 2019.

9. H. Hertz, "Über die Berührung fester elastischer Körper," Journal für die reine und angewandte Mathematik, vol. 92, no. 156-171, p. 22, 1882.

10. I. McColl, J. Ding, and S. Leen, "Finite element simulation and experimental validation of fretting wear," Wear, vol. 256, no. 11-12, pp. 1114-1127, 2004.

11. T. Yue and M. A. Wahab, "Finite element analysis of fretting wear under variable coefficient of friction and different contact regimes," Tribology International, vol. 107, pp. 274-282, 2017.

12. M. Rohanifar and H. Hatami-Marbini, "Numerical modelling of mechanical properties of 2D cellular solids with bimodulus cell walls," Mechanics of Advanced Materials and Structures, pp. 1-9, 2019.

13. H. Hatami-Marbini and M. Rohanifar, "Nonlinear mechanical properties of prestressed branched fibrous networks," Biophysical Journal, vol. 120, no. 3, pp. 527-538, 2021.

14. A. Jafar, R. Gholamhossein, and R. Fazel, "Stress analysis of clamped-free grid composite cylindrical shell under various end loadings," Journal of Central South University, vol. 21, no. 7, pp. 2667-2672, 2014.

15. J. Arashmehr, G. H. Rahimi, and S. F. Rasouli, "An experimental and numerical investigation of a grid composite cylindrical shell subjected to transverse loading," Strojniški vestnik-Journal of Mechanical Engineering, vol. 59, no. 12, pp. 755-762, 2013.

16. B. Hajshirmohammadi and M. Khonsari, "On the entropy of fatigue crack propagation," International Journal of Fatigue, vol. 133, p. 105413, 2020.

17. B. Hajshirmohammadi and M. Khonsari, "A simple approach for predicting fatigue crack propagation rate based on thermography," Theoretical and Applied Fracture Mechanics, vol. 107, p. 102534, 2020.

18. R. Hojjati Talemi, "Numerical modelling techniques for fretting fatigue crack initiation and propagation," 2014.

19. S. Habibian, "Analysis and Control of Fiber-Reinforced Elastomeric Enclosures (FREEs)," arXiv preprint arXiv:1912.07380, 2019.

20. K. W. Buffinton, B. B. Wheatley, S. Habibian, J. Shin, B. H. Cenci, and A. E. Christy, "Investigating the mechanics of human-centered soft robotic actuators with finite element analysis," in 2020 3rd IEEE International Conference on Soft Robotics (RoboSoft), 2020: IEEE, pp. 489-496.

21. S. Habibian et al., "Design and implementation of a maxi-sized mobile robot (Karo) for rescue missions," ROBOMECH Journal, vol. 8, no. 1, pp. 1-33, 2021.

22. S. Satvati, M. A. Rowshanzamir, and S. M. Hejazi, "A copmparison between the bearing capacities of strip footing on soil slope reinforced by plannar and tubular form of braid and geogrid elements," in The 3rd Pan-American conference on geosynthetics, 2016.

23. S. Satvati, M. A. Rowshanzamir, and S. M. Hejazi, "EVALUATION OF THE BEARING CAPACITY OF SHALLOW FOOTING ON REINFORCE SOIL SLOPE WITH BRAID."

24. T. Chakherlou and A. P. Jirandehi, "A precise, novel, 3D simulation and analysis of simple bolted plates, clamped and subjected to longitudinal tensile loads," in Proceedings of the international modern achievements on aerospace and related sciences, 2015.

25. T. Chakherlou and A. P. Jirandehi, "A profound study on the effects of friction coefficient on torque tightened, longitudinally loaded, bolted connections," in Proceedings of the international modern achievements on aerospace and related sciences, 2015.

Cite this Article: Behnam Hajshirmohammadi, Mohammad Mehdizadeh (2021). Finite Element Investigation of Moment Effect on Fretting Fatigue. International Journal of Current Science Research and Review, 4(4), 265-272 